\title{
Seleção de termossifões para aplicação em um sistema híbrido fotovoltaico/térmico
}

\section{Thermosyphon selection for application in a hybrid photovoltaic/thermal system}

\author{
Pedro Leineker Ochoski Machadoํㅡ, Vitor Otávio Ochoski Machado², Victor Vaurek Dimbarre \\ Romeu Miqueias Szmoski ${ }^{1}$, Paulo Henrique Dias dos Santos ${ }^{2}$, Thiago Antonini Alves ${ }^{1 *}$
}

\section{RESUMO}

Neste trabalho foi realizada uma análise térmica experimental de termossifões distintos para aplicação em um sistema híbrido fotovoltaico/térmico. Os termossifões foram fabricados a partir de tubos de cobre possuindo comprimento total de $840 \mathrm{~mm}$. O fluido de trabalho utilizado foi água destilada com razão de preenchimento de $50 \%$ do volume do evaporador. O evaporador tem comprimento de $650 \mathrm{~mm}$, enquanto a seção adiabática e o condensador têm comprimentos de $80 \mathrm{~mm}$ e $110 \mathrm{~mm}$, respectivamente. O condensador foi resfriado por convecção forçada de água, a seção adiabática foi isolada e o evaporador foi aquecido por um resistor elétrico. Testes experimentais foram realizados para uma carga térmica de $80 \mathrm{~W}$ a $140 \mathrm{~W}$ em uma posição a $25^{\circ}$ da horizontal (evaporador acima do condensador). A análise térmica foi baseada na distribuição de temperaturas ao longo dos dispositivos passivos de transferência de calor, sua resistência térmica e eficiência térmica. O Termossifão B, que possui maior diâmetro, apresentou melhores resultados nas condições testadas, se mostrando assim a melhor escolha entre os dois termossifões para compor um sistema híbrido fotovoltaico/térmico.

Palavras-chave: Termossifão; Energia Solar; Sistema Híbrido Fotovoltaico/Térmico.

\begin{abstract}
In this work, a experimental thermal analysis of different thermosyphons for application in a hybrid photovoltaic/thermal system was performed. Thermosyphons were manufactured from copper tubes having a total length of $840 \mathrm{~mm}$. The working fluid used was distilled water with a filling rate of $50 \%$ of the evaporator volume. The evaporator has a length of $650 \mathrm{~mm}$, while the adiabatic section and the condenser have lengths of $80 \mathrm{~mm}$ and $110 \mathrm{~mm}$, respectively. The condenser was cooled by water forced convection, the adiabatic section was insulated, and the evaporator was heated by an electric resistor. Experimental tests were performed for a heat load of 80 to $140 \mathrm{~W}$ in a position at $25^{\circ}$ from the horizontal (evaporator above the condenser). The thermal analysis was based on the distribution of temperatures throughout the devices, their thermal resistance and thermal efficiency. The Thermosyphon B, which has a larger diameter, performed better in all the parameters of the thermal analysis in the tested conditions, showing itself as the best choice between the two thermosyphons for the application of thermal control in photovoltaic panels.
\end{abstract}

Keywords: Thermosyphon; Solar Energy; Hybrid Photovoltaic/Thermal System.

\footnotetext{
${ }^{1}$ Universidade Tecnológica Federal do Paraná (UTFPR), Campus Ponta Grossa.

*E-mail: antonini@utfpr.edu.br

${ }^{2}$ Universidade Tecnológica Federal do Paraná (UTFPR), Campus Curitiba, Sede Ecoville.
} 


\section{INTRODUÇÃO}

Pesquisas acadêmicas e políticas ambientais evidenciam a busca por novas fontes e tecnologias de exploração de energias renováveis, substituindo o uso de fontes com elevados índices de degradação ambiental (ADAMS et al., 2018). Dentre as fontes renováveis destaca-se a energia solar, que consiste no aproveitamento da luz e do calor fornecido pela radiação solar para geração de energia elétrica a partir de painéis fotovoltaicos, ou energia térmica em coletores solares (KABIR et al., 2018). Apesar de a energia solar possuir, teoricamente, potencial para suprir a demanda energética global por completo, sua participação na matriz energética brasileira no ano de 2019 representou apenas $0,8 \%$ do total de energia gerada, porém apresentando um crescimento de 90,2\% em relação ao ano anterior (MME, 2019).

Essa baixa contribuição está muito relacionada à eficiência dos dispositivos utilizados para o aproveitamento dessa energia, como por exemplo painéis fotovoltaicos. Fatores como a temperatura superficial do painel fotovoltaico influenciam diretamente em seu desempenho em níveis que dependem das características do painel fotovoltaico, como sua potência máxima, área de superfície e eficiência. Estudos realizados com um painel fotovoltaico de potência nominal de $20 \mathrm{~W}$ indicam que esse possui um coeficiente de temperatura de $0,9 \%$ por ${ }^{\circ} \mathrm{C}$, ou seja, a cada acréscimo de $1^{\circ} \mathrm{C}$ em sua temperatura superficial, ocorre um decréscimo de 0,9\% em sua eficiência energética (HALLAL et al., 2020).

Nesse sentido, diversos estudos estão sendo realizados de forma a controlar a temperatura de painéis fotovoltaicos. Dentre esses estudos, Chow et al. (2009) investigaram a influência do uso ou não de uma camada de vidro sobre as células solares e Hallal et al. (2020) investigaram o uso de ventiladores para resfriamento dos painéis fotovoltaicos. Tubos de calor e/ou termossifões também foram incorporados a painéis fotovoltaicos, como pode ser observado em Akbarzadeh \& Wadowski (1996), Pei et al. (2010) e Hu et al. (2016). Ao aplicar termossifões em painéis fotovoltaicos existem possibilidades de, além de realizar o resfriamento do painel fotovoltaico, utilizar o calor dissipado pelos painéis fotovoltaicos para aquecer um fluido de trabalho, transformandoo em um sistema híbrido fotovoltaico/térmico, elevando ao mesmo tempo a eficiência energética e exergética do painel fotovoltaico. 
Nesse contexto, o presente trabalho visa realizar a seleção de um termossifão para aplicação em um sistema híbrido fotovoltaico/térmico. Para isso, uma comparação entre dois termossifões com diferentes dimensões foi realizada a partir de uma análise térmica experimental, considerando a distribuição de temperatura ao longo do dispositivo passivo de transferência de calor, sua resistência térmica e sua eficiência térmica.

\section{TERMOSSIFÕES}

Um termossifão, também denominado tubo de calor assistido por gravidade, é um dispositivo passivo de transferência de calor com condutividade térmica efetiva elevada. É um dispositivo com um ciclo fechado que pode transferir calor de forma rápida e efetiva entre duas fontes (uma quente e outra fria). É composto por um tubo evacuado e preenchido por um fluido de trabalho, transportando energia na forma de calor entre seus extremos a partir do calor latente de vaporização, relacionado com a evaporação e condensação do fluido de trabalho (REAY et al., 2014; ZOHURI, 2016).

Esse dispositivo passivo é composto por três regiões com diferentes funções em sua operação e seu funcionamento está ilustrado na Figura 1. O evaporador, região inferior do termossifão, é a região em que está contido o fluido de trabalho. Essa região fica em contato com uma fonte quente e, ao absorver calor, o fluido de trabalho inicia o processo de evaporação. Devido ao fato de o interior do termossifão ser evacuado, o processo de evaporação ocorre a uma temperatura menor do que ocorreria à pressão atmosférica, uma vez que a pressão no interior do dispositivo atinge valores extremamente baixos em relação ao ambiente externo. Ao evaporar, o vapor do fluido de trabalho, devido à gradientes de pressão, desloca-se pelo centro do termossifão até atingir a região superior, denominada de condensador. O condensador fica em contato com uma fonte fria, podendo ser um escoamento de fluido frio, por exemplo. Nessa região o calor absorvido no evaporador e carregado pelo vapor do fluido de trabalho é dissipado para o ambiente externo, ocasionando a condensação do vapor de fluido. Devido à ação da gravidade, o fluido de trabalho condensado retorna à região do evaporador escoando pelas paredes do termossifão, fechando o ciclo termodinâmico. Entre o evaporador e o condensador está localizada a seção adiabática, onde não há troca de calor com o ambiente externo, podendo estar ausente dependendo da aplicação (REAY et al., 2014; ZOHURI, 2016; KRAMBECK et al., 2019). 
Figura 1 - Princípio de funcionamento de um termossifão

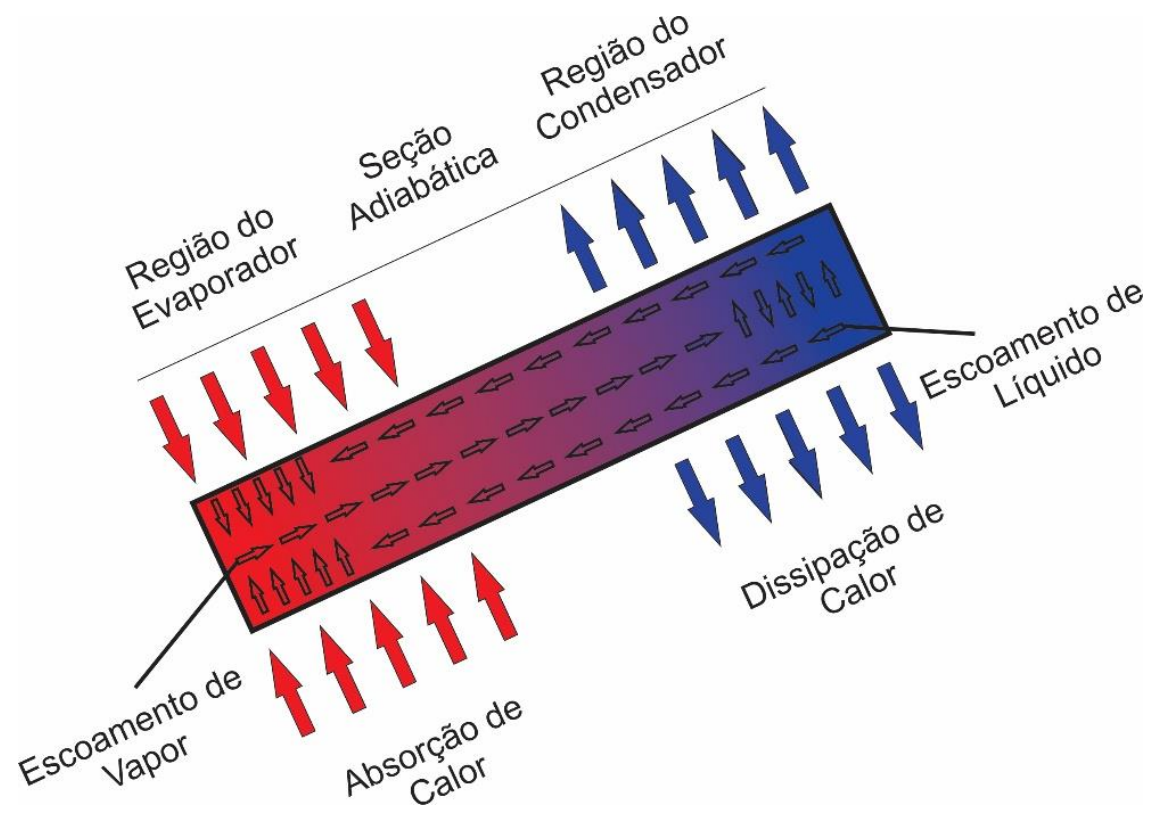

As aplicações dos termossifões são diversas, podendo ser utilizados para recuperação de calor em um sistema de gases de exaustão ou pré-aquecendo o ar em trocadores de calor de caldeira. Também são amplamente utilizados em locais de frio extremo para troca de calor com a parte mais quente do solo, podendo auxiliar na manutenção de estradas em operação no inverno e até em ambientes aquecidos. Além disso, em regiões frias contendo linhas de transporte de óleo, os termossifões atuam captando o calor do óleo do tubo e transferindo-o para o ambiente externo, reduzindo o calor que a base recebe e transfere para o solo, evitando o degelo e a instabilidade da fundação. Os termossifões também são utilizados em coletores solares a vácuo, altamente eficazes e aplicáveis no aquecimento de água para uso diário, ambientes e também piscinas. Outra área de aplicação é a secagem e desidratação de produtos alimentícios e tecidos, além do resfriamento eletroeletrônico (KRAMBECK et al., 2020, 2021; NISHIDA et al., 2020).

\section{METODOLOGIA}

Essa seção descreve os materiais e procedimentos experimentais utilizados para realização desse estudo. 


\section{Aparato Experimental}

O aparato experimental utilizado nesse estudo é mostrado na Figura 2(a) e é composto por uma fonte de alimentação Politerm $^{\mathrm{TM}} 16 \mathrm{E}$, um sistema de aquisição de

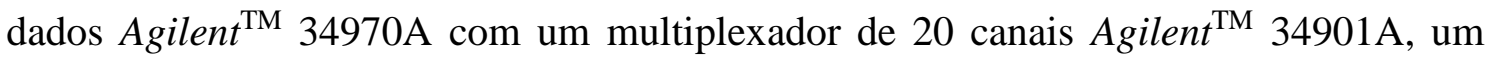
banho ultratermostatizado Solab ${ }^{\mathrm{TM}}$ SL-130, um laptop Dell ${ }^{\mathrm{TM}}$, um nobreak $N H S^{\mathrm{TM}}$ e um medidor de vazão de área variável Omega Engineering ${ }^{\mathrm{TM}}$ FL-2051 com válvula reguladora. Um diagrama esquemático do aparato experimental é ilustrado na Figura 2(b).

Figura 2 - Aparato experimental

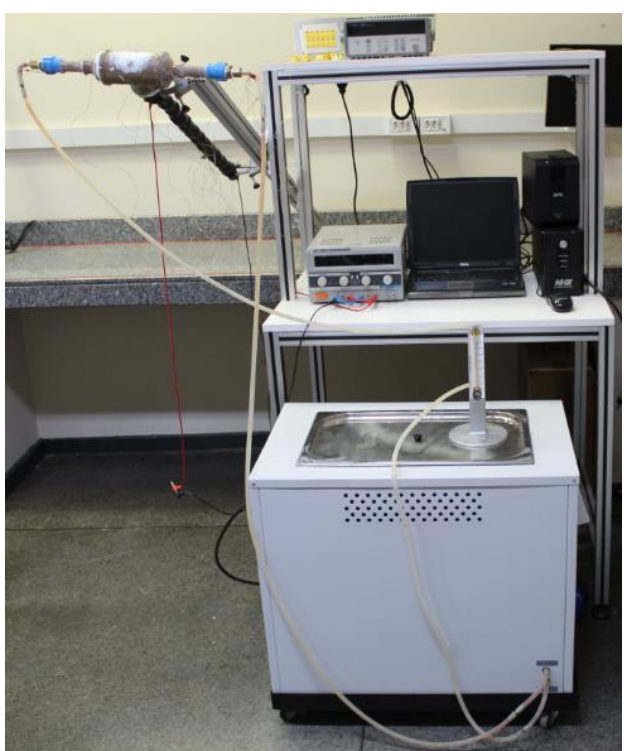

(a)

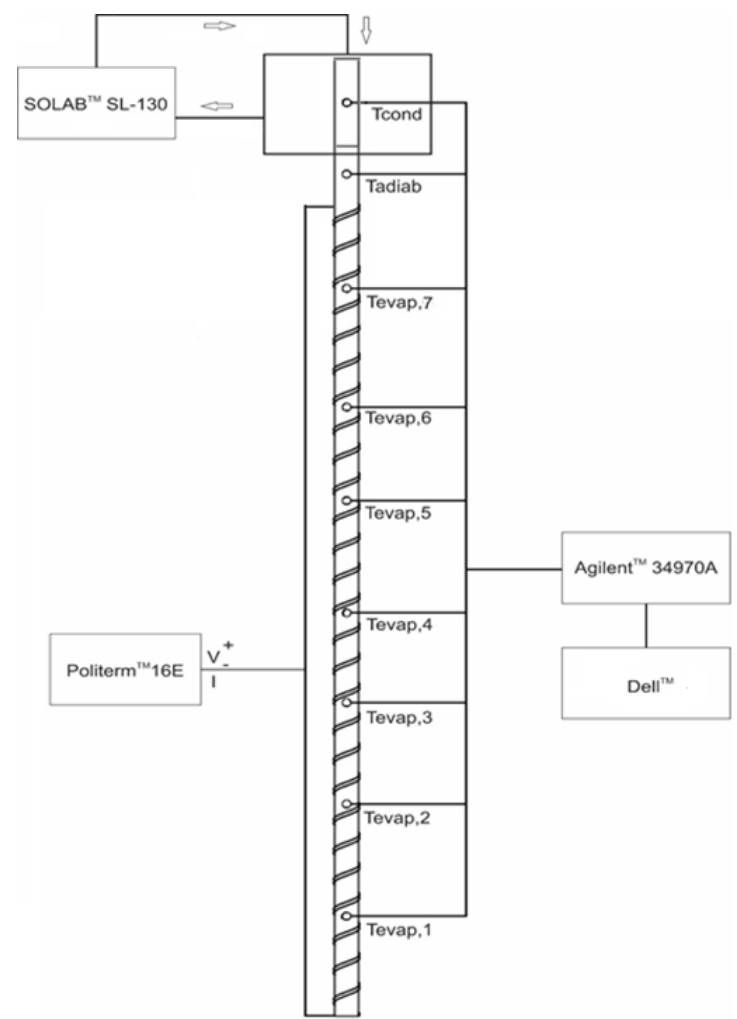

(b)

As regiões do evaporador e da seção adiabática foram cobertas com uma fita Kapton $^{\mathrm{TM}}$ de alta condutividade térmica. Uma fita resistiva Omega Engineering ${ }^{\mathrm{TM}}$ foi enrolada sobre o evaporador e conectada à fonte de alimentação. $\mathrm{O}$ condensador foi posicionado no interior de um tê de PVC com $60 \mathrm{~mm}$ de diâmetro que atua como um manifold. O tê, a partir de conexões e mangueiras de silicone, foi conectado ao banho ultratermostatizado, permitindo o escoamento de água sob essa região. Um total de 11 termopares do tipo K Omega Engineering ${ }^{\mathrm{TM}}$ foram utilizados para aquisição de dados de temperatura durante os testes experimentais, sete igualmente espaçados no evaporador ( $T_{\text {evap, }, 1}, T_{\text {evap }, 2}, T_{\text {evap }, 3}, T_{\text {evap }, 4}, T_{\text {evap }, 5}, T_{\text {evap }, 6}$, e $\left.T_{\text {evap }, 7)}\right)$ um na seção adiabática $\left(T_{\text {adiab }}\right)$, um no condensador $\left(T_{c o n d}\right)$, e um na entrada $\left(T_{e n t}\right)$ e outro na saída $\left(T_{\text {sai }}\right)$ de água no tê de PVC. 


\section{Procedimento Experimental}

Os termossifões foram fabricados a partir de tubos de cobre ASTM B75, possuindo comprimento total de $840 \mathrm{~mm}$. O fluido de trabalho utilizado foi água destilada com uma razão de preenchimento de 50\% do volume do evaporador. $\mathrm{O}$ evaporador tem comprimento de $650 \mathrm{~mm}$, enquanto a seção adiabática e o condensador têm comprimentos de $80 \mathrm{~mm}$ e $110 \mathrm{~mm}$, respectivamente. A metodologia utilizada na construção dos termossifões (preparação, limpeza, montagem, teste de estanqueidade, procedimento de evacuação e preenchimento com fluido de trabalho) foi baseada nas informações contidas em Antonini Alves et al. (2018). Os termossifões foram construídos com diferentes diâmetros em suas regiões e foram projetados para aplicação de controle térmico de sistema híbrido fotovoltaico/térmico. A Tabela 1 apresenta as dimensões dos dois termossifões analisados experimentalmente nesse trabalho.

Tabela 1 - Dimensões dos termossifões

\begin{tabular}{ccccccc}
\hline \multirow{3}{*}{ Termossifão } & \multicolumn{2}{c}{ Evaporador } & \multicolumn{2}{c}{ Seção adiabática } & \multicolumn{2}{c}{ Condensador } \\
\cline { 2 - 7 } & $\begin{array}{c}\text { Diâmetro } \\
\text { Externo }\end{array}$ & $\begin{array}{c}\text { Diâmetro } \\
\text { Interno }\end{array}$ & $\begin{array}{c}\text { Diâmetro } \\
\text { Externo }\end{array}$ & $\begin{array}{c}\text { Diâmetro } \\
\text { Interno }\end{array}$ & $\begin{array}{c}\text { Diâmetro } \\
\text { Externo }\end{array}$ & $\begin{array}{c}\text { Diâmetro } \\
\text { Interno }\end{array}$ \\
\hline A & $12,7 \mathrm{~mm}$ & $11,1 \mathrm{~mm}$ & $12,7 \mathrm{~mm}$ & $11,1 \mathrm{~mm}$ & $12,7 \mathrm{~mm}$ & $11,1 \mathrm{~mm}$ \\
B & $22,2 \mathrm{~mm}$ & $20,6 \mathrm{~mm}$ & $22,2 \mathrm{~mm}$ & $20,6 \mathrm{~mm}$ & $22,2 \mathrm{~mm}$ & $20,6 \mathrm{~mm}$ \\
\hline
\end{tabular}

Considerando os testes experimentais, o evaporador foi aquecido pelo efeito Joule resultante da dissipação de potência da fonte de alimentação na fita resistiva. Cargas térmicas de $80 \mathrm{~W}$ a $140 \mathrm{~W}$ com passo de $20 \mathrm{~W}$ foram utilizadas durante os testes. Um escoamento de água com vazão volumétrica de $0,8 \mathrm{~L} / \mathrm{min}$ sobre o condensador foi responsável pela dissipação de calor absorvido pelo termossifão, simulando seu funcionamento durante sua aplicação destinada. A água usada para o processo de resfriamento assim como a temperatura ambiente foram mantidas a $16,0^{\circ} \mathrm{C} \pm 0,5^{\circ} \mathrm{C}$ pelo banho ultratermostatizado e um sistema de ar condicionado Carrier $^{\mathrm{TM}}$. As cargas térmicas foram aplicadas por um tempo de 40 minutos e os termossifões foram mantidos a uma inclinação de $25^{\circ}$ com a horizontal (evaporador abaixo do condensador), correspondendo à latitude da cidade de Ponta Grossa/PR/Brasil: 2505'42" Sul.

Para a análise térmica foi considerada a distribuição de temperaturas dos termossifões analisados, sua temperatura de operação $\left(T_{\text {adiab }}\right)$, queda de temperatura entre evaporador $\left(T_{\text {evap }}\right)$ e condensador $\left(T_{\text {cond }}\right)$ a partir da resistência térmica $\left(R_{t h}\right.$ - Eq. (1)) e eficiência térmica $\left(\eta_{t h}\right.$ - Eq. (2)). Tratando-se das equações, $q$ representa a carga térmica 
aplicada, $c_{p}$ o calor específico a pressão do fluido de resfriamento do condensador do termossifão, $\dot{m}$ a vazão mássica de água sobre o condensador do termossifão, $T_{\text {ent }}$ a temperatura de entrada da água e $T_{s a i}$ a temperatura de saída da água no manifold.

$$
\begin{aligned}
R_{\text {th }} & =\frac{T_{\text {evap }}-T_{\text {cond }}}{q}, \\
\eta_{\text {th }} & =100 \frac{\dot{m}_{a} c_{p}\left(T_{\text {sai }}-T_{\text {ent }}\right)}{q} .
\end{aligned}
$$

\section{RESULTADOS}

A distribuição de temperaturas em função do tempo para o Termossifão A é apresentada na Figura 3, ao passo que os resultados obtidos para o Termossifão B estão apresentados na Figura 4. Ambas as figuras apresentam o comportamento típico e esperado durante os testes experimentais de um termossifão. Inicialmente as temperaturas estão em equilíbrio, aumentando posteriormente devido à aplicação da carga térmica, e estabilizando novamente ao atingir o regime permanente.

Como pode ser observado, as temperaturas no evaporador foram maiores que na seção adiabática, que por sua vez também foram maiores que as temperaturas no condensador, o que era esperado. Além disso, a temperatura da água na saída do manifold de PVC foi maior do que na entrada durante todos os testes experimentais, mostrando coerência com o esperado.

No início dos testes experimentais, durante a aplicação da carga térmica de $80 \mathrm{~W}$, foram verificados alguns picos de temperatura. Esses picos ocorrem pelo fato de que, no início dos testes experimentais, a região do evaporador que contém o fluido de trabalho apresenta uma maior massa a ser aquecida, apresentando assim menores temperaturas do que a região do evaporador que não apresenta fluido de trabalho, uma vez que os termossifões foram preenchidos com uma razão de preenchimento de 50\%. A partir do momento em que se iniciam os processos de evaporação e condensação do fluido de trabalho dentro do termossifão, os picos de temperatura se reduzem e, em seguida, apresentam um equilíbrio. 
Figura 3 - Distribuição de temperaturas em função do tempo para o Termossifão A

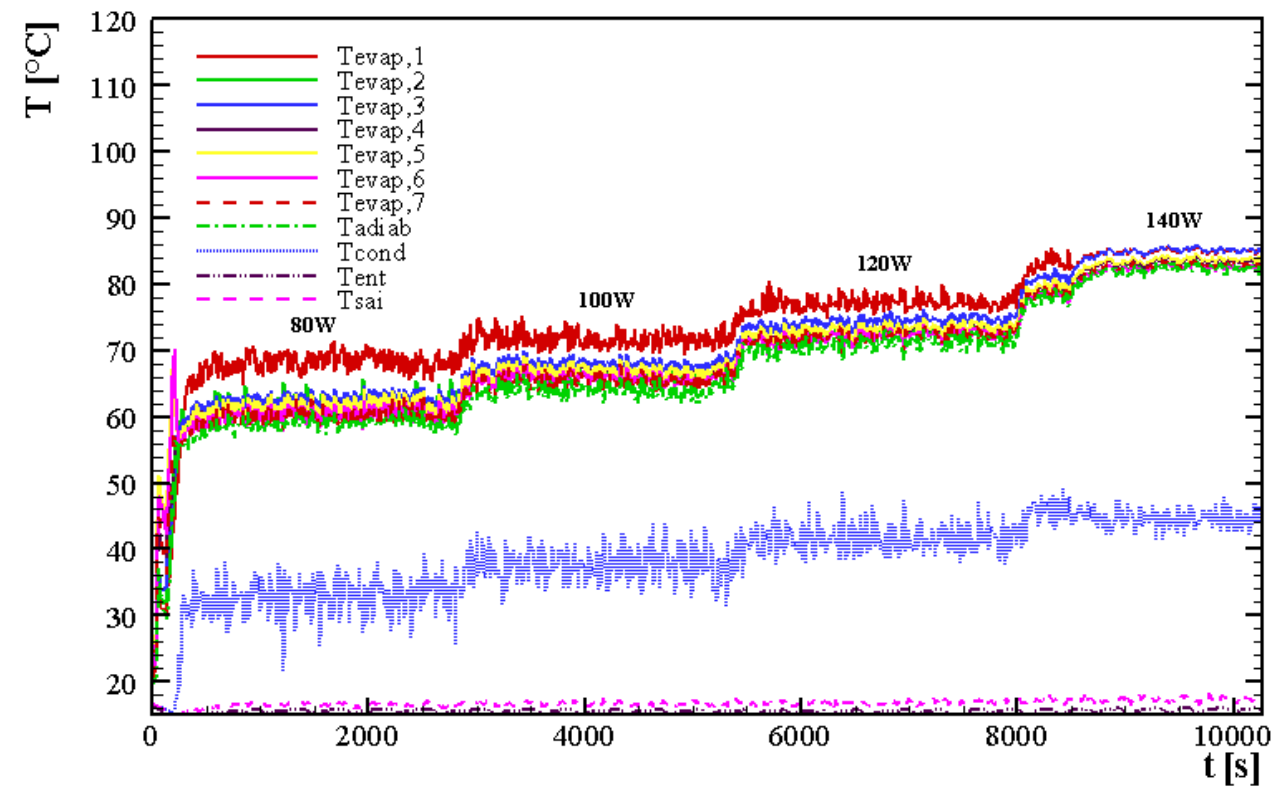

Figura 4 - Distribuição de temperaturas em função do tempo para o Termossifão B

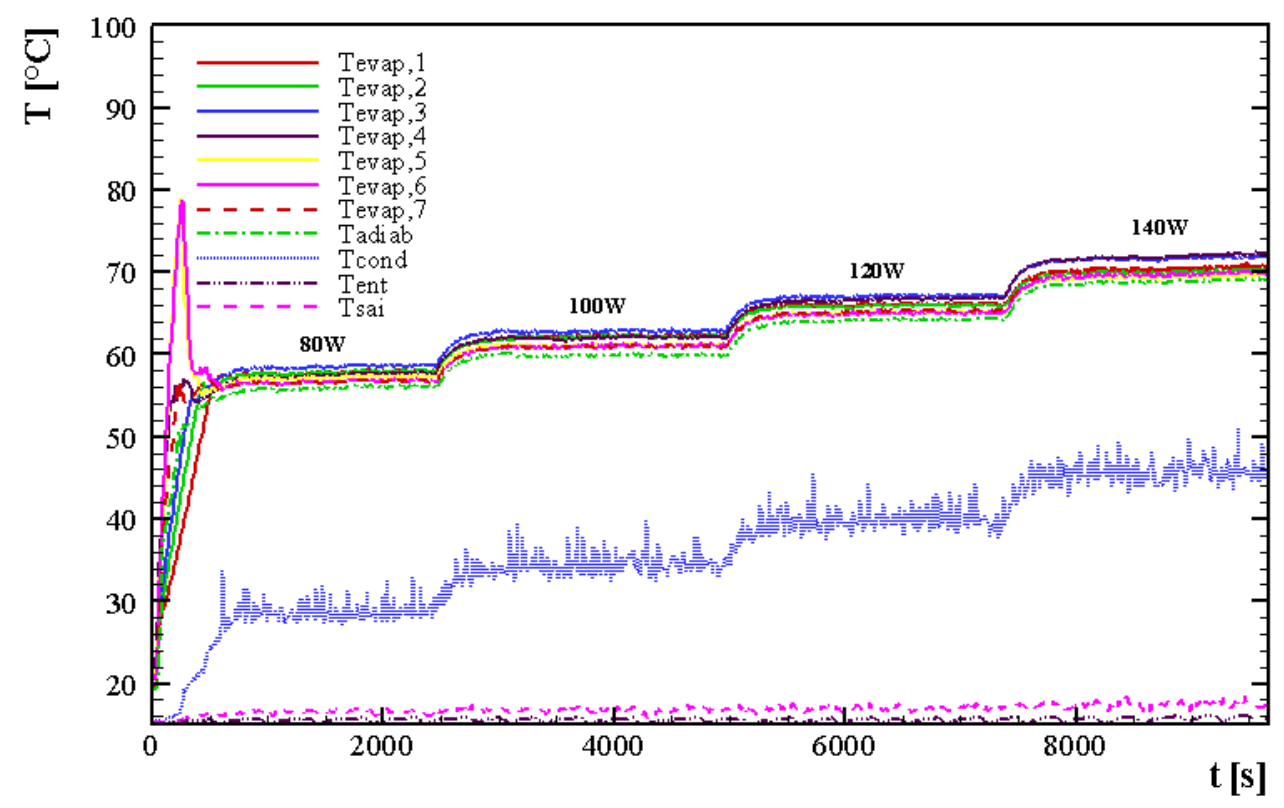

Em geral, comparando as Figuras 3 e 4, pode ser observado que as temperaturas apresentadas pelo Termossifão B apresentaram uma estabilidade e consistência maior do que as do Termossifão A. Além disso, para todas as cargas térmicas aplicadas, o Termossifão B apresentou menores temperaturas em todas as suas regiões, sendo um indício que esse dispositivo passivo transfere a energia absorvida no evaporador para a água no manifold de PVC de forma mais eficiente. 
Na Figura 5 é apresentada uma comparação da temperatura de operação entre os dois termossifões em função da carga térmica aplicada. Pode ser verificado que para todas as cargas térmicas aplicadas, o Termossifão B apresentou menor temperatura de operação que o Termossifão A. Indicando que o Termossifão A possui um pior desempenho térmico, uma vez que é desejável que o dispositivo passivo possa transferir a carga térmica aplicada com a menor temperatura possível, indicando maior eficiência de transferência de calor.

Figura 5 - Temperatura de operação em função da carga térmica aplicada

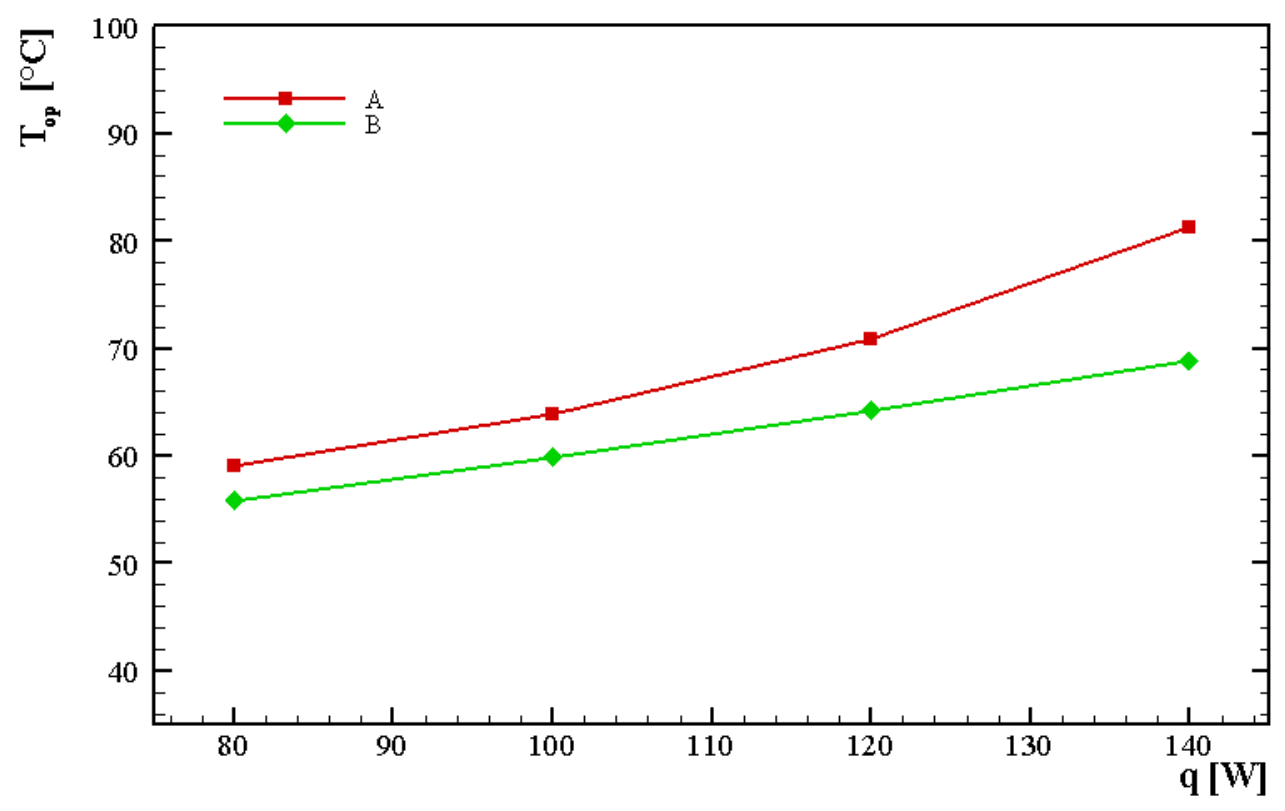

A Figura 6 apresenta os valores experimentais obtidos para a resistência térmica juntamente com sua incerteza experimental para os dois termossifões analisados em função da carga térmica aplicada. A incerteza considerada foi de $1,27^{\circ} \mathrm{C}$ para cada termopar, além de $0,003 \mathrm{~V}$ e $0,003 \mathrm{~A}$ para a fonte de alimentação e de $1,5.10^{-6} \mathrm{~m}^{3} / \mathrm{s}$ para o medidor de vazão volumétrica.

A partir da Figura 6 pode ser verificado que o Termossifão B apresentou menores valores associados à resistência térmica do que o Termossifão A. Isso corrobora com os resultados apresentados nas Figuras 3 a 5, uma vez que, considerando um mesmo gradiente de temperaturas, quanto menor for a resistência térmica, maior será a carga térmica dissipada, pela Eq. (1), o que indica que o termossifão de maior diâmetro possui melhor desempenho térmico nas condições operacionais analisadas. 
Figura 6 - Resistência Térmica em Função da Carga Térmica Aplicada

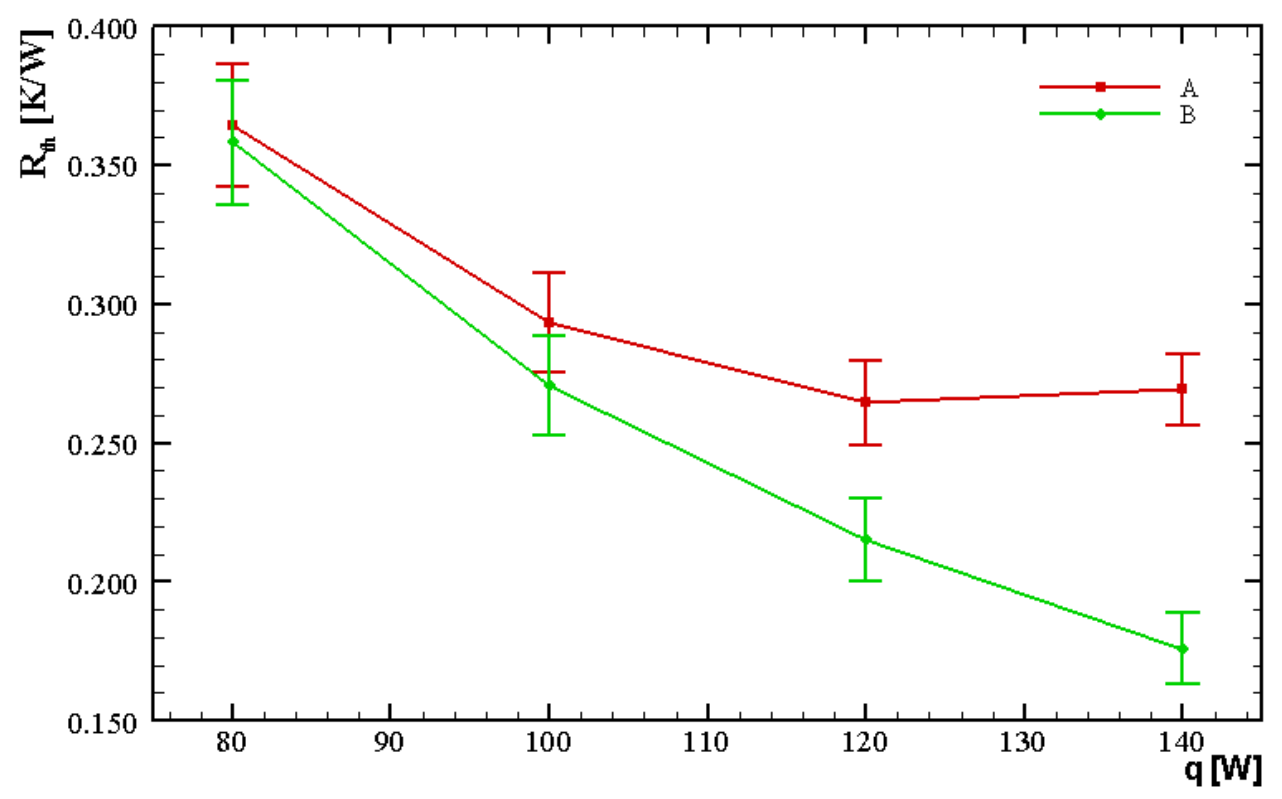

Finalmente, na Tabela 2 são apresentados os resultados encontrados experimentalmente para a eficiência térmica de cada termossifão a partir da Eq. (2). Esses resultados experimentais confirmam que o foi observado nas Figuras 3 a 6. Com exceção da primeira carga térmica, o Termossifão B apresentou valores maiores de eficiência térmica que o Termossifão A. Neste caso, com a análise dos resultados experimentais, conclui-se então que o Termossifão $\mathrm{B}$, com maior diâmetro, deve ser utilizado para realizar o controle térmico de um sistema híbrido fotovoltaico/térmico.

Tabela 2 - Eficiência térmica dos termossifões

\begin{tabular}{cc}
\hline Termossifão & $\begin{array}{c}\boldsymbol{\eta}_{\text {th }} \\
{[\%]}\end{array}$ \\
\hline \multirow{3}{*}{ A } & 69,0 \\
& 66,4 \\
& 63,7 \\
& 65,9 \\
B & 67,9 \\
& 70,4 \\
& 72,4 \\
& 75,4 \\
\hline
\end{tabular}




\section{CONCLUSÃO}

Nesse trabalho foi detalhada a análise térmica de dois termossifões fabricados com tubos de cobre e preenchidos com água destilada como fluido de trabalho. A análise térmica experimental foi baseada na distribuição de temperaturas ao longo dos dispositivos, temperatura de operação, resistência térmica e eficiência térmica. Os testes experimentais consistiram em simular a operação dos termossifões em um ambiente de laboratório, dissipando calor na região do evaporador dos termossifões a partir da dissipação de potência em uma fita resistiva (efeito Joule), e resfriando o condensador a partir de escoamento de água em sua superfície através de um manifold de PVC. Como resultado, em todos os parâmetros térmicos analisados, o Termossifão B, que apresenta maior diâmetro, obteve melhor desempenho térmico. Isso quer dizer que o termossifão apresentou menores temperaturas em todas as suas regiões, menor temperatura de operação, menor resistência térmica e maior eficiência térmica para todas as cargas térmicas dissipadas. Dessa forma, conclui-se que o Termossifão B é o mais recomendado para uso no controle térmico de um sistema híbrido fotovoltaico/térmico, uma vez que apresenta melhor desempenho na transferência de calor do que o Termossifão A.

\section{AGRADECIMENTOS}

Agradecimentos são prestados à CAPES, à Pró-Reitoria de Pesquisa e PósGraduação da UTFPR, à Diretoria de Pesquisa e Pós-Graduação, ao Programa de PósGraduação em Engenharia Mecânica e ao Departamento Acadêmico de Mecânica da UTFPR/Campus Ponta Grossa.

\section{REFERÊNCIAS}

ADAMS, S.; KLOBODU, E.K.M.; APIO, A. Renewable and non-renewable energy, regime type and economic growth. Renewable Energy, v. 125, p. 755-767, 2018.

ANTONINI ALVES, T.; KRAMBECK, L.; SANTOS, P.H.D. Heat pipe and thermosyphon for thermal management of thermoelectric cooling. In: ARANGUREN, P. (Ed.). Bringing thermoelectricity into reality.London/UK: InTech, 2018. p. 353374. 
AKBARZADEH, A.; WADOWSKI, T. Heat pipe-based cooling systems for photovoltaic cells under concentrated solar radiation. Applied Thermal Engineering, v. 16, p. 81-87, 1996.

CHOW, T.T. et al. Energy and exergy analysis of photovoltaic-thermal collector with and without glass cover. Applied Energy, v. 86, p. 310-316, 2009.

HALLAL, J.; HAMMOUD, M.; MOUSSA, T. Experimental optimization of the Si photovoltaic panels cooling system on maximum allowable temperature criteria.

Renewable Energy Focus, v. 35, p. 178-181, 2020.

HU, M. et al. Experimental study of the effect of inclination angle on the thermal performance of heat pipe photovoltaic/thermal (PV/T) systems with wickless heat pipe and wire-meshed heat pipe. Applied Thermal Engineering, v. 106, p. 651-660, 2016.

KABIR, E. et al. Solar energy: Potential and future prospects. Renewable and Sustainable Energy Reviews, v. 82, p. 894-900, 2018.

KRAMBECK, L. et al. Experimental research of capillary structure technologies for heat pipes. Acta Scientiarum. Technology, v. 42, p. e48189-e48189, 2020.

KRAMBECK, L. et al. Experimental thermal performance of different capillary structures for heat pipes. Energy Engineering (Print), v. 118, p. 1-14, 2021.

KRAMBECK, L. et al. Thermal performance evaluation of different passive devices for electronics cooling. Thermal Science, v. 23, p. 1151-1160, 2019.

Mistério de Minas e Energia (MME). Resenha Energética Brasileira, exercício de 2018, (preliminar). MME, Brasil, 2019.

NISHIDA, F.B. et al. Experimental investigation of heat pipe thermal performance with microgrooves fabricated by wire electrical discharge machining (wire-EDM). Thermal Science, v. 24, p. 701-711, 2020.

PEI, G. et al. Comparative study of a heat pipe PV/T and a water-thermosiphon PV/T. In: 2010 ASIA-PACIFIC POWER AND ENERGY ENGINEERING CONFERENCE, 2010, Chengdu/CHI. Proceedings [...] Chengdu/CHI: IEEE, 2010. p. 1-4.

REAY, D.; McGLEN, R.; KEW, P. Heat Pipes: Theory, Design and Applications. Amsterdam/NED: Butterworth-Heinemann, 2013.

ZOHURI, B. Heat Pipe Design and Technology: Modern Applications for Practical Thermal Management. New York/USA: Springer, 2016.

Recebido em: 01/09/2021

Aprovado em: 12/09/2021

Publicado em: 16/09/2021 